\title{
Effects of Low w6:w3 Ratio in Sow Diet and Seaweed Supplement in Piglet Diet on Performance, Colostrum and Milk Fatty Acid Profiles, and Oxidative Status
}

\author{
Thi Xuan Nguyen ${ }^{1,2, * \mathbb{C}}$, Alessandro Agazzi ${ }^{1}{ }^{1}$, Marcello Comi ${ }^{3}$, Valentino Bontempo ${ }^{1} \mathbb{D}$, \\ Invernizzi Guido $\left.{ }^{1}{ }^{(}\right)$, Sara Panseri ${ }^{1}$, Helga Sauerwein ${ }^{4}{ }^{\circledR}$, Peter David Eckersall ${ }^{2}{ }^{\circledR}$, \\ Richard Burchmore ${ }^{2}$ and Giovanni Savoini ${ }^{1}$ \\ 1 Department of Health, Animal Science and Food Safety 'Carlo Cantoni' (VESPA), Università degli Studi \\ di Milano, Via dell’ Università 6, 26900 Lodi, Italy; alessandro.agazzi@unimi.it (A.A.); \\ valentino.bontempo@unimi.it (V.B.); guido.invernizzi@unimi.it (I.G.); sara.panseri@unimi.it (S.P.); \\ giovanni.savoini@unimi.it (G.S.) \\ 2 College of Medical, Veterinary and Life Sciences, School of Veterinary Medicine, University of Glasgow, \\ Garscube Estate, Switchback Road, Bearsden G61 1QH, UK; David.Eckersall@glasgow.ac.uk (P.D.E.); \\ Richard.Burchmore@glasgow.ac.uk (R.B.) \\ 3 Department of Human Science and Quality of Life Promotion, Università Telematica San Raffaele Roma, \\ Via di Val Cannuta 247, 00166 Rome, Italy; marcello.comi@uniroma5.it \\ 4 Institute of Animal Science, Physiology and Hygiene Unit, University of Bonn, 53115 Bonn, Germany; \\ sauerwein@uni-bonn.de \\ * Correspondence: thixuan.nguyen@unimi.it
}

Received: 9 September 2020; Accepted: 29 October 2020; Published: 5 November 2020

Simple Summary: Feeding maternal animals divergent ratios of omega-6 ( $\omega 6)$ and omega-3 ( $\omega 3)$ fatty acids can change not only their health, physiological condition, and performance but also do the same for their offspring. In swine production, various $\omega 6: \omega 3$ ratios have been tested, but the search for an optimal proportion in the sow diet is still in progress. For piglets, weaning oxidative stress has been alleviated by supplementing with abundant sources of bioactive compounds. In this case, brown seaweed, a rich source of natural antimicrobials and antioxidants, can be a good candidate, but its supplementation in piglet diet is limited. This study explores the hypothesis that feeding a low $\omega 6: \omega 3$ ratio diet to sows during gestation and lactation, together with the supplementation of Ascophyllum nodosum for piglets during the post-weaning period, could benefit piglets' performance and oxidative status more than the respective single treatment provided to the mother or the piglet. Results showed that the low dietary $\omega 6: \omega 3$ ratio (4:1) and seaweed supplement did not affect the post-weaning piglets' growth rate and oxidative status. However, a low $\omega 6: \omega 3$ ratio diet alone improved weaning survival rate, suckling piglets' weight gain, and total $\omega 3$ fatty acids in colostrum and milk.

Abstract: The ratio of omega-6 ( $\omega 6)$ to omega-3 ( $\omega 3)$ polyunsaturated fatty acids (PUFAs) in the diet contributes to animal health and performance modulations because they have mostly opposite physiological functions. Increasing $\omega 3$ PUFAs content in the maternal diet can stimulate antioxidative capacity in sow and piglets; however, the optimal ratio of $\omega 6$ and $\omega 3$ PUFAs in the sow diet is still under discussion. Rich sources of bioactive constituents such as brown seaweed are an excellent supplementation to promote animal health and antioxidant status. However, the knowledge of the effects of this compound, specifically in post-weaning piglets, is still limited. Moreover, the combined effect of a low $\omega 6: \omega 3$ PUFAs ratio in sow diet and seaweed supplementation in post-weaning piglets' diet has never been studied. This research aims to assess the combined effect of a low $\omega 6: \omega 3$ ratio in sow diets and seaweed supplementation in piglet diets on their growth and oxidative status. We also assessed the impact of a low $\omega 6: \omega 3$ ratio in the maternal diet on reproduction, milk fatty acid (FA) 
profile, and plasma leptin concentration. Two sow diets $(n=8$ each) contained either a control ratio (CR, 13:1 during gestation, starting from day 28 (G28) and 10:1 during lactation) or a low ratio (LR, 4:1 from G28 until the end of lactation (L-End)) of $\omega 6: \omega 3$ FA by adding soybean oil or linseed oil, respectively. Reproductive performance was evaluated. Colostrum and milk at lactation day 7 (L7) and L-End were collected to analyze FA profile. Plasma was collected at G28, G79, G108, L7, L14, and L-End for determination of leptin and oxidative status. At weaning, 20 male piglets were selected per sow group to form 4 diet treatments ( $n=10$ each), which were supplemented with or without $4 \mathrm{~g} / \mathrm{kg}$ seaweed. Recording of growth performance and collection of blood were performed at days 0 , 7,15 , and 21 of post-weaning for oxidative status. LR diet increased $(p<0.05)$ the survival rate of piglets at weaning, and individual and litter weight gains. Colostrum and milk at L7 and L-End had lower $(p<0.05) \omega 6: \omega 3$ ratio in LR sows. Interaction between dietary treatments on sows and piglets was revealed for all examined growth parameters at most time points $(p<0.05)$. LR diet did not affect plasma leptin levels and oxidative status. These findings suggest that the seaweed supplement during post-weaning could not improve growth rate and oxidative status of piglets born from mothers receiving a low dietary $\omega 6: \omega 3$ ratio (4:1) during gestation and lactation. However, this low ratio was beneficial for weaning survival rate, sucking piglets' weight gain, and $\omega 3$ enrichment in colostrum and milk.

Keywords: sow; $\omega 6: \omega 3$ polyunsaturated fatty acids; seaweed; piglet

\section{Introduction}

In pig production, there is a growing interest in lowering the ratio of omega-6 ( $\omega 6)$ :omega-3 ( $\omega 3)$ polyunsaturated fatty acids (PUFAs) below 10:1 in maternal diets by using divergent sources of $\omega 3$ PUFAs (e.g., fish oil, linseed oil) to promote the health and performance of sows and piglets [1-5]. The enrichment of $\omega 3$ PUFAs in the diet has been shown to stimulate the antioxidative capacity in sow plasma and glutathione peroxidase activity (GSH-Px, an enzyme protecting cells against oxidative damage) in piglet liver, and decreased lipid peroxidation in piglet plasma [6]. A previous study found that increasing $\omega 3$ PUFAs in the maternal diet enhanced anti-inflammatory properties and reduced the pro-inflammatory effects of $\omega 6$ PUFAs, thus maintaining homeostasis [7]. A recent meta-analysis supports this notion in human studies [8], which showed that increasing the portion of $\omega 3$ PUFAs in the diet enhances the antioxidant defense mechanisms. However, there continues to be a debate about the optimal ratio of $\omega 6$ and $\omega 3$ PUFAs in the sow diet and how these effects can be transmitted from mother to offspring via milk, especially effects on piglets' performance and oxidative status.

For piglets, weaning is the most stressful event in life: the transition from a milk-based to a solid diet and changes in the environment and social relationships can reduce feed intake and conversion efficiency, disrupting gut mucosal barriers, and leading to reduced growth and health [9]. Moreover, piglets undergo oxidative stress and inflammation after weaning that can further participate in poor performance [10]. These adverse outcomes can be alleviated by supplementing with abundant sources of bioactive compounds [10-13]. Brown seaweed Ascophyllum nodosum (A. nodosum) is a rich source of natural antioxidants [14] and antimicrobials [15], which can inhibit or impede oxidative damage by neutralizing free radicals in the cell [16]. Therefore, supplementing A. nodosum in the post-weaning diet can promote piglet health and performance. To our knowledge, only a few studies have investigated the effect of intact $A$. nodosum meal on the oxidative status of post-weaning piglets $[17,18]$. Moreover, none of them examined the possible combined or additive effect of low $\omega 6$ : $\omega 3$ PUFAs ratio in sow diet and A. nodosum supplementation in post-weaning piglets' diet.

Herein, we hypothesized that feeding a low $\omega 6: \omega 3$ ratio diet to sows during gestation and lactation, together with the supplementation of $A$. nodosum for piglets during the post-weaning period could benefit piglets' performance and oxidative status more than the respective single treatment 
provided to the mother or the piglet. With this purpose, we also considered the effects of maternal dietary low $\omega 6: \omega 3$ ratio on their reproductive performance, milk fatty acids (FA) profile, regulation of plasma leptin concentrations (which indicates sows' body fat content), and oxidative status.

\section{Materials and Methods}

\subsection{Animals and Housing}

The sow experiment was conducted on a commercial swine farm (Arioli and Sangalli Agricultural Company S.S., Genzone, Italy). Sows were artificially inseminated with pooled semen (Topdelta boar) and kept in groups from one week after artificial insemination until one week before farrowing. Sixteen multiparous sows had similar body weight $(202.57 \pm 7.16 \mathrm{~kg}$, mean \pm SEM) and body condition score $(2.36 \pm 0.12$, mean \pm SEM) at the beginning of the trial. On day 108 , gestating sows were moved to individual farrowing crates and stayed there until weaning. Within $24 \mathrm{~h}$ of birth, ear notching and tagging, iron injection, needle teeth clipping, and tail docking were performed.

The piglet trial was performed at the Animal Production Research and Teaching Centre, University of Milan (Lodi, Italy). Piglets were weaned at day $26( \pm 1.76)$ of age $(6.46 \pm 0.15 \mathrm{~kg}$ of body weight, mean $\pm \mathrm{SE}$ ), and 20 male piglets per dietary treatment were selected from the sows (40 piglets in total). They were housed in individual pens $\left(0.47 \mathrm{~m}^{2} /\right.$ pen $)$ equipped with a bite nipple drinker and self-feeder. The experimental protocols were approved by the Ethical Committee of the University of Milan (OPBA 67/2018) and the Italian Ministry of Health (authorization n. 168/2019 PR).

\subsection{Experimental Diets}

Sows were randomly allocated to one of two diet treatments that contained either control ratio (CR, 13:1 during gestation, starting from day 28 (G28) and 10:1 during lactation) or a low ratio (LR, 4:1, from G28 until the end of lactation) of $\omega 6: \omega 3$ PUFAs. The $\omega 6$ and $\omega 3$ fatty acids for this study were derived from soybean oil and linseed oil (Mazzoleni s.pa., Bergamo, Italy). The $\omega 6$ and $\omega 3$ PUFAs content (per total fatty acids) of soybean oil was $54.3 \%$ and $8.5 \%,(\omega 6: \omega 3=6.26)$, of linseed oil was $16.2 \%$ and $52.9 \%(\omega 6: \omega 3=0.31)$. Experimental diets were calculated to be isonitrogenous and isoenergetic and to meet the estimated nutrient requirements for sows during gestation and lactation [19], according to the total amount of the basal diet (Table 1) provided to adjust the final ratios of $\omega 6: \omega 3$ PUFAs in the diets to 13:1 during gestation and 10:1 during lactation, and 4:1 from G28 until the end of lactation (Table 2).

Experimental diets (fed as a liquid feed by mixing with water) were supplied from day (d) 28 of gestation until the end of lactation. Soybean oil and linseed oil were added to the barley meal at a rate of $10 \%$ to create a mixture before the daily feeding of the sows. The gestation diet was provided at $2.4 \mathrm{~kg} / \mathrm{d}$ with $15 \mathrm{~g} / \mathrm{d}$ of soybean or linseed oil from d 28 to d 79 and $2.9 \mathrm{~kg} / \mathrm{d}$ with $18 \mathrm{~g} / \mathrm{d}$ of soybean or linseed oil from $\mathrm{d} 80$ to the end of gestation. Sows were fed per pen ( $8 \mathrm{sows} / \mathrm{pen})$. The lactation diet was fed at $1 \mathrm{~kg} / \mathrm{d}$ on the farrowing day (d 0) and then gradually increased to a maximum of $7.5 \mathrm{~kg} / \mathrm{d}$ at weaning. During lactation, soybean oil and linseed oil were added daily to the individually basal diet administered according to the lactation feeding plan. Feed was provided twice a day and sows had unlimited access to freshwater. Feed was offered (increased daily) based on the sows' feed consumed during the previous day.

For piglets, the meal-based commercial diet (Table 3) was supplemented with or without $4 \mathrm{~g} / \mathrm{kg}$ seaweed powder (A. nodosum; Prodotti Arca S.r.l, Monza, Italy), providing 6.5\% crude protein, 3.0\% crude fat, $22.5 \%$ ash, and $52.5 \%$ polysaccharides on an as fed basis. Four groups ( $n=10$ each) were formed: CRCT (maternal $\omega 6: \omega 3=13: 1$ during gestation and 10:1 during lactation, without seaweed (SW) supplementation); CRSW ( $\omega 6: \omega 3=13: 1$ during gestation and 10:1 during lactation, with $S W$ ); LRCT ( $\omega 6: \omega 3=4: 1$ during gestation and lactation, without SW); and LRSW ( $\omega 6: \omega 3=4: 1$ during gestation and lactation, with SW). 
Table 1. Composition of Basal Sow Diets.

\begin{tabular}{|c|c|c|}
\hline Item & Gestation & Lactation \\
\hline \multicolumn{3}{|l|}{ Ingredients ( $\mathrm{g} / \mathrm{kg}$ as fed basis) } \\
\hline Corn & 284.60 & 249.10 \\
\hline Barley & 224.20 & 216.70 \\
\hline Wheat bran & 208.00 & 115.80 \\
\hline Distillers grains & 125.00 & 40.00 \\
\hline Biscuit & 50.20 & 52.10 \\
\hline Rice & 35.00 & 35.00 \\
\hline Commercial concentrate ${ }^{*}$ & 25.00 & 250.00 \\
\hline Soybean oil & 12.90 & 14.00 \\
\hline Fish meal & - & 14.50 \\
\hline Mineral-vitamin premix ${ }^{* *}$ & 20.00 & 11.70 \\
\hline HCl-Lysine & 11.20 & 15.00 \\
\hline \multicolumn{3}{|l|}{ Composition (\% DM) } \\
\hline Crude protein & 15.85 & 19.92 \\
\hline Crude fat & 4.55 & 4.93 \\
\hline Crude fiber & 5.69 & 5.66 \\
\hline Ash & 5.68 & 4.46 \\
\hline $\mathrm{Ca}$ & 1.70 & 1.21 \\
\hline $\mathrm{P}$ & 0.56 & 0.57 \\
\hline $\mathrm{Ca} / \mathrm{P}$ & 3.04 & 2.12 \\
\hline Lysine & 1.04 & 1.34 \\
\hline Methionine & 0.18 & 0.22 \\
\hline Met + Cis & 0.37 & 0.50 \\
\hline
\end{tabular}

* Providing (as fed basis): $32.36 \%$ crude protein, $6.80 \%$ crude fat, $6.77 \%$ crude fiber, $0.80 \% \mathrm{Na}, 2.43 \%$ lysine, $0.56 \%$ methionine. ${ }^{* *}$ Providing (per $\mathrm{kg}$ of complete diet): vitamin A, 10,000 IU; vitamin $\mathrm{D}_{3}, 2000 \mathrm{IU}$; vitamin E, $48 \mathrm{IU}$; vitamin $\mathrm{K}_{3}, 1.5 \mathrm{mg}$; riboflavin, $6 \mathrm{mg}$; niacin, $40 \mathrm{mg}$; biotin, $0.2 \mathrm{mg}$; $\mathrm{d}$-pantothenic, $17 \mathrm{mg}$; folic acid, $2 \mathrm{mg}$; choline, $166 \mathrm{mg}$; vitamin $\mathrm{B}_{6}, 2 \mathrm{mg}$; and vitamin $\mathrm{B}_{12}, 28 \mathrm{mg}$. Fe (as $\left.\mathrm{FeSO}_{4}\right), 90 \mathrm{mg} ; \mathrm{Cu}\left(\right.$ as $\left.\mathrm{CuSO}_{4}\right), 15 \mathrm{mg}$; $\mathrm{Zn}\left(\right.$ as $\mathrm{ZnSO}_{4}$ ), $50 \mathrm{mg}$; $\mathrm{Mn}\left(\right.$ as $\left.\mathrm{MnO}_{2}\right), 54 \mathrm{mg}$; I (as KI), $0.99 \mathrm{mg}$; and Se $\left(\right.$ as $\left.\mathrm{Na}_{2} \mathrm{SeO}_{3}\right), 0.25 \mathrm{mg}$.

Table 2. Fatty Acid (g/100 g total fatty acids) of sow diets.

\begin{tabular}{ccccc}
\hline Item & Gestation CR & Gestation LR & Lactation CR & Lactation LR \\
\hline $10: 0$ & 0.26 & 0.22 & - & - \\
$12: 0$ & 0.35 & 0.30 & 1.80 & 1.56 \\
$14: 0$ & 0.25 & 0.21 & - & - \\
$16: 0$ & 20.23 & 18.08 & 17.58 & 16.06 \\
$16: 1 \omega 7$ & 0.50 & 0.42 & - & - \\
$18: 0$ & 3.06 & 3.30 & 4.36 & 4.40 \\
$18: 1 \omega 9$ cis & 19.88 & 19.80 & 24.51 & 23.84 \\
$18: 1 \omega 7$ & 1.05 & 1.03 & - & 0.12 \\
$18: 2 \omega 6$ cis 9,12 & 49.79 & 44.73 & 46.92 & 42.90 \\
$18: 3 \omega 3$ & 3.72 & 11.12 & 4.83 & 11.12 \\
$20: 0$ & 0.28 & 0.24 & - & - \\
$20: 1 \omega 9$ & 0.41 & 0.35 & - & - \\
$22: 0$ & 0.23 & 0.20 & - & - \\
$\omega 6$ & 49.79 & 44.73 & 46.92 & 42.90 \\
$\omega 3$ & 3.72 & 11.12 & 4.83 & 11.12 \\
$\omega 6: \omega 3$ & 13.40 & 4.02 & 9.71 & 3.88 \\
\hline
\end{tabular}

Control ratio (CR): sow diet with $\omega 6: \omega 3$ ratio = 13:1 during gestation, starting from day 28 (G28) and 10:1 during lactation; low ratio (LR): sow diet with $\omega 6: \omega 3$ ratio $=4: 1$ from G28 until the end of lactation. 
Table 3. Ingredients and Chemical Composition of the Basal Diet (CT) of post-weaning piglets. Seaweed powder (SW) was added to the basal diet at $4 \mathrm{~g} / \mathrm{kg}$ feed rate.

\begin{tabular}{|c|c|}
\hline Item & Post-Weaning Basal Diet \\
\hline \multicolumn{2}{|l|}{ Ingredients (g/kg as fed basis) } \\
\hline Barley & 220.0 \\
\hline Wheat & 161.7 \\
\hline Soy protein concentrate (Soicomil R) & 98.0 \\
\hline Wheat, flaked & 80.0 \\
\hline Corn & 80.0 \\
\hline Corn, flaked & 60.0 \\
\hline Soybean, meal & 59.0 \\
\hline Biscuits & 50.0 \\
\hline Whey & 50.0 \\
\hline Dextrose, mono & 40.0 \\
\hline Barley, flaked & 40.0 \\
\hline Soybean oil & 20.0 \\
\hline Dicalcium phosphate & 10.0 \\
\hline Cocoa oil & 10.0 \\
\hline L-Lysine & 6.0 \\
\hline DL-Methionine & 3.6 \\
\hline L-Threonine & 3.5 \\
\hline Sodium chloride & 2.7 \\
\hline Vitamin + trace elements & 2.5 \\
\hline L-Valine $(96.5 \%)$ & 2.2 \\
\hline L-Tryptophan & 0.8 \\
\hline \multicolumn{2}{|l|}{ Composition $(\%, \mathrm{DM})$} \\
\hline Dry matter (DM) & 89.60 \\
\hline Crude protein & 20.10 \\
\hline Crude fat & 5.68 \\
\hline Fiber & 3.29 \\
\hline Neutral detergent fiber (NDF) & 12.91 \\
\hline Acid detergent fiber (ADF) & 4.67 \\
\hline Acid detergent lignin (ADL) & 0.97 \\
\hline Lysine (Lys), total & 1.57 \\
\hline Cystine & 0.32 \\
\hline Methionine (Met), total & 0.66 \\
\hline Threonine, total & 1.09 \\
\hline Tryptophan, total & 0.32 \\
\hline Valine & 1.08 \\
\hline Phenylalanine & 0.85 \\
\hline Tyrosine & 0.55 \\
\hline Isoleucine & 0.74 \\
\hline Leucine & 0.32 \\
\hline Net energy (NE, Mcal/kg) & 2.90 \\
\hline
\end{tabular}

\subsection{Recording and Sampling}

The sows' body weights and body condition scores (BCS) were assessed at the beginning of the trial (G28), middle of gestation (G79), at transferring time to the farrowing crates (G108), and at the end of lactation (L-End). The BCS was estimated using the five points scale $(1=$ emaciated, $2=$ thin, $3=$ ideal, $4=$ fat, and $5=$ obese; [20]). Two sows from the $\mathrm{CR}$ group had to be removed from the study because they had early parturition.

Piglets born, born alive, and born dead (stillborn, mummified, crushed, and abnormal) were counted within $24 \mathrm{~h}$ postpartum to calculate the survival rate at birth. The number of live piglets was recorded at $\mathrm{d} 7, \mathrm{~d} 14$, and at weaning to calculate the weaning survival rate. Piglets were weighed at $24 \mathrm{~h}$ postpartum, $\mathrm{d} 7, \mathrm{~d} 14$, and at weaning to calculate average daily weight gain. 
Colostrum and milk samples (8-40 mL per sample) were collected after an overnight fast ( $12 \mathrm{~h})$, by manual milking of all functional mammary glands of each sow within $24 \mathrm{~h}$ postpartum and on $\mathrm{d} 7$, $\mathrm{d} 14$, and at weaning. Samples were aliquoted and stored at $-80^{\circ} \mathrm{C}$ until analysis.

Blood samples were collected at G28, G79, G108, L7, L14, and L-End using ethylenediaminetetraacetic acid (EDTA) tubes and centrifuged ( $15 \mathrm{~min} ; 3000 \times \mathrm{g}$; room temperature). The EDTA plasma was aspirated and transferred to storage tubes before being stored at $-80^{\circ} \mathrm{C}$ until analysis.

For post-weaning piglets, feed supply and residuals per head were recorded every morning, from $\mathrm{d} 0$ (weaning day) until d 21 to calculate average daily feed intake and feed conversion ratio. On d 0, 7, 15 , and 21, piglets were weighed, and blood samples were collected from the jugular vein. The EDTA plasma obtained was stored at $-80^{\circ} \mathrm{C}$ until analysis.

\subsection{Colostrum and Milk Fatty Acid Analysis}

Fat in colostrum and milk was extracted [21] and then derivatized [22]. The resulting fatty acid methyl esters (FAMEs) were measured in a gas chromatographer equipped with a flame ionization detector (Trace ${ }^{\mathrm{TM}}$ GC Ultra, Thermo Fisher Scientific S.p.A., Rodano, Milan, Italy). The internal standard was nonadecanoic acid (C19:0; $10 \mathrm{mg} / \mathrm{mL}$ of hexane), and the carrier gas was helium (He). FAMEs were separated by a fused silica capillary column (Rt-2560, $100 \mathrm{~m} \times 0.25 \mathrm{~mm} \times 0.25 \mu \mathrm{m}$ ) and followed the given program: $50{ }^{\circ} \mathrm{C}$ for $6 \mathrm{~min}$; increased by $10{ }^{\circ} \mathrm{C} \mathrm{min}^{-1}$ until $170{ }^{\circ} \mathrm{C}$, constant for $30 \mathrm{~min}$; increased by $4{ }^{\circ} \mathrm{C} \mathrm{min}^{-1}$ to $220^{\circ} \mathrm{C}$, constant for $20 \mathrm{~min}$. Individual FAME was verified by comparing peak retention times with standard mixtures (Supelco 37 FAME Mix, Bellefonte, PA, USA) and pure standard methyl esters from Sigma-Aldrich (Saint Louis, MO, USA).

\subsection{Leptin and Indicators of Oxidative Status in Plasma}

Leptin was measured by an in-house developed ELISA validated for use on porcine samples [23]; the intra- and inter-assay CVs were 7.27 and $8.70 \%$, respectively.

Oxidative damage was measured on levels of hydroperoxides (by-products of free radicals) using the d-ROMs (derivatives of reactive oxygen metabolites) test [24] with modifications [25]. Oxidative damage of proteins was assessed by the AOPP (advanced oxidation products of proteins) assay [26]. The AOPP concentrations are expressed both as molar concentrations and per mg of total protein. Total protein concentrations were measured with the Bradford assay [27]. Oxidative damage of lipids was estimated using the TBARS (thiobarbituric acid reactive substances) assay [28]. The total antioxidative capacity was assessed via the FRAP (ferric reducing ability of plasma) assay [29]. The intra- and inter-assay variations of all four assays were below $8 \%$.

\subsection{Statistical Analysis}

Data relative to the length of gestation and lactation, body weight (BW) and BW gain/loss, reproductive performance, fatty acids (FAs) profile, leptin, and oxidative stress indicators of sows were analyzed using the General Linear Model (GLM) procedure in SAS Studio 3.8, on SAS version 9.04.01M6P11072018 (SAS Institute Inc., Cary, NC, USA). The statistical model considered the $\omega 6: \omega 3$ ratio, day, and their interactions as fixed effects, and individual sows as the repeated effect.

Data on post-weaning piglet performance and oxidative stress indicators were analyzed with a repeated-measures model using a MIXED procedure. The statistical model considered $\omega 6: \omega 3$ ratio, seaweed supplement, day, and their interactions as fixed effects, individual piglets as a repeated effect, and weaning time as a random effect. GENMOD procedure (using generalized estimating equations (GEE) method) was performed to fit the generalized linear models on data that were not normally distributed. This included gain-to-feed ratio of piglets; some FAs ( $\sum$ SFA, TLA, $\sum \omega 3$ and ALA in colostrum; DGLA, EPA, and DHA in milk at $\mathrm{d} 7$ of lactation; GLA, DGLA, ETA, EPA, DHA, and $\omega 6: \omega 3$ ratio in milk at the end of lactation); some oxidative stress indicators in sows (leptin at L7, advanced oxidation products of proteins (AOPP) at G79 and G108, thiobarbituric acid reactive substances (TBARS) at L-End, Ferric reducing ability of plasma (FRAP) at G108 and L7, derivatives of 
reactive oxygen metabolites (d-ROM) at G28, L7, and L-End) and piglets (AOPP and FRAP at $\mathrm{d}$ 7, 15 and 21; TBARS at weaning and $\mathrm{d} 15$; d-ROM from weaning to $\mathrm{d} 21$ ).

Data are presented as LSM (least square means) \pm SEM in tables and LSM \pm SE in figures. Figures were plotted using GraphPad Prism version 8.4.2 (GraphPad software, La Jolla, CA, USA). Significance was set at $p \leq 0.05$.

\section{Results}

\subsection{Sow Reproductive Performance}

Low dietary $\omega 6: \omega 3$ ratio (LR) had no effect on sow body weight, weight gain and loss during gestation and lactation (data unshown). The LR diet did not affect total number of piglets born $(\mathrm{LSM} \pm \mathrm{SE}$ : LR $13.75 \pm 0.83$ piglets; CR $16.33 \pm 0.96$ piglets; $p>0.05$ ) but decreased the number of born alive by 3.45 piglets compared to CR diet (LR $11.38 \pm 0.46$ piglets; CR $14.83 \pm 0.54$ piglets; $p<0.001$ ). Total piglets weaned per sow of LR group (10.38 \pm 0.57 piglets) and of CR group (11.17 \pm 0.65 piglets) were similar $(p>0.05)$. Consequently, the LR diet increased the survival rate of piglets at weaning (LR $90.95 \pm 3.66 \%$; CR $75.95 \pm 4.23 \%$; $p<0.05$ ).

The LR diet increased individual and litter weight gains compared with the CR diet $(p<0.05$, Figure 1). The LR diet did not affect piglet weight at weaning (LR $7.05 \pm 0.44 \mathrm{~kg}$; CR $5.84 \pm 0.50 \mathrm{~kg}$; $p>0.05$ ) and piglet weight gain from d 7 to weaning (LR $4.49 \pm 0.42 \mathrm{~kg} ; \mathrm{CR} 3.32 \pm 0.49 \mathrm{~kg} ; p>0.05$ ).

A1

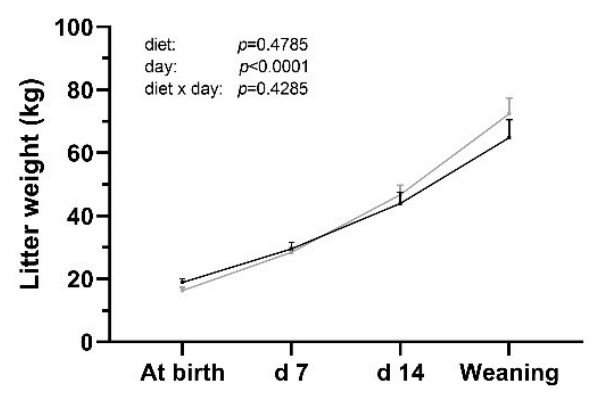

A3

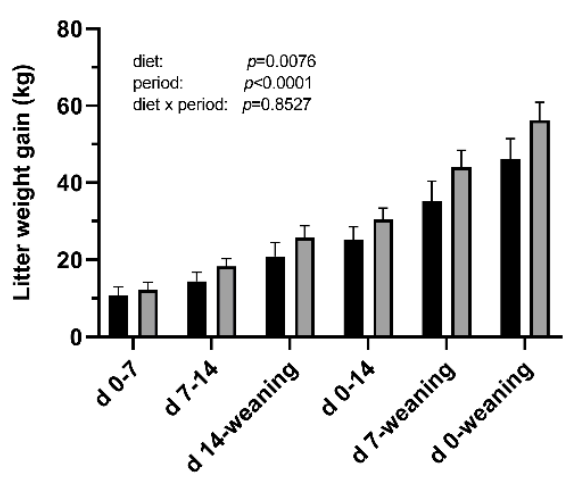

A2

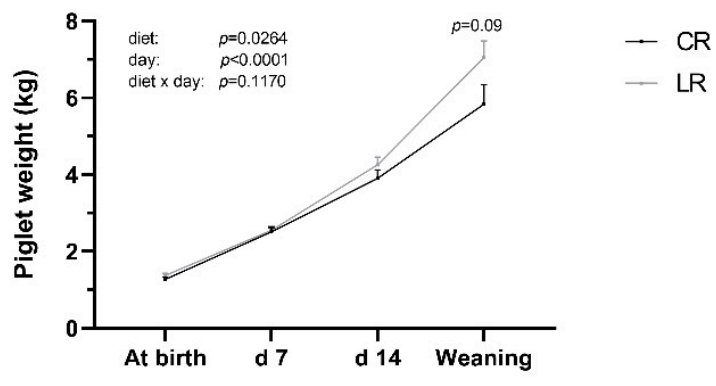

A4

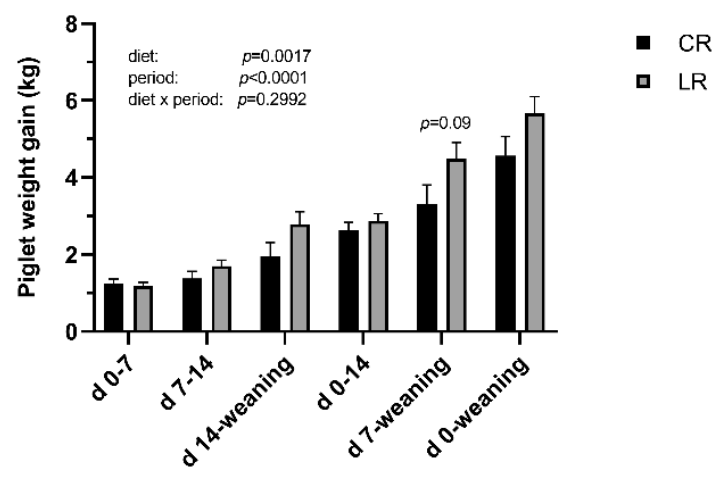

Figure 1. Low dietary $\omega 6: \omega 3$ ratio in sow improves body weight gain of neonatal piglets. Sows were fed diets with $\omega 6: \omega 3$ ratio $=13: 1$ during gestation, starting from day 28 (G28) and 10:1 during lactation $(\mathrm{CR})$ or $\omega 6: \omega 3$ ratio $=4: 1$ from G28 until the end of lactation (LR). A1: Litter weight development during neonatal period. A2: Piglet weight development. A3: Litter weight gain per subperiod. A4: Piglet weight gain per subperiod. Data are $\mathrm{LSM} \pm \mathrm{SE}, n=6$ for $\mathrm{CR}$ group and $n=8$ for LR group. 


\subsection{Growth Performance of Post-Weaning Piglets}

Low maternal dietary $\omega 6: \omega 3$ ratio and seaweed supplementation in the post-weaning piglets' diet had no influence $(p>0.05)$ on piglet growth (Table 4 , Table S1). However, interactions between dietary treatments on sow and piglet were revealed $(p<0.05)$ for BW, average daily gain $(\mathrm{ADG})$, average daily feed intake (ADFI), and gain-to-feed ratio (G:F), mostly related to CRSW vs. CRCT groups. At d 21, BW was higher $(p<0.05)$ in the CRSW than the CRCT group. ADG was improved $(p<0.05)$ during post-weaning. Higher ADFI $(p<0.05)$ was observed during post-weaning for CRSW and LRCT groups compared to LRSW group. G:F ratio was ameliorated $(p<0.05)$ during the first two weeks of post-weaning in CRSW vs. CRCT piglets.

Table 4. Growth performance of post-weaning piglets fed seaweed (SW).

\begin{tabular}{|c|c|c|c|c|c|c|c|c|}
\hline \multirow{2}{*}{$\begin{array}{c}\text { Sow Diets (SD) } \\
\text { Piglet Diets (PD) * }\end{array}$} & \multicolumn{2}{|c|}{ CR } & \multicolumn{2}{|c|}{ LR } & \multirow{2}{*}{ SEM $^{1}$} & \multicolumn{3}{|c|}{$p$-Value } \\
\hline & CT & SW & CT & SW & & SD & PD & $\mathrm{SD} \times \mathrm{PD}$ \\
\hline No. of piglets ** & 10 & 10 & 10 & 10 & & & & \\
\hline \multicolumn{9}{|l|}{$\mathrm{BW}^{2}(\mathrm{~kg})$} \\
\hline d 0 & 6.19 & 6.19 & 6.66 & 6.36 & 0.55 & $\mathrm{~ns}^{4}$ & ns & ns \\
\hline $\mathrm{d} 7$ & 6.86 & 7.21 & 7.58 & 6.89 & 0.59 & ns & ns & ns \\
\hline $\mathrm{d} 15$ & 9.56 & 10.72 & 10.62 & 9.32 & 0.98 & ns & ns & 0.018 \\
\hline $\mathrm{d} 21$ & $12.41^{b}$ & $14.14^{\mathrm{a}}$ & 13.64 & 12.13 & 1.17 & ns & ns & 0.010 \\
\hline \multicolumn{9}{|l|}{$\mathrm{ADG}^{2}(\mathrm{~g} / \mathrm{d})$} \\
\hline d 0 to 7 & 51.86 & 101.30 & 157.50 & 100.20 & 62.74 & ns & ns & ns \\
\hline d 0 to 15 & 202.76 & 279.59 & 275.82 & 211.51 & 55.73 & ns & ns & 0.017 \\
\hline d 0 to 21 & $276.15^{b}$ & $358.55^{\mathrm{a}}$ & 345.63 & 289.71 & 52.20 & ns & ns & 0.013 \\
\hline \multicolumn{9}{|l|}{$\mathrm{ADFI}^{2}(\mathrm{~g} / \mathrm{d})$} \\
\hline d 0 to 7 & 154.46 & 194.17 & 222.59 & 196.79 & 44.58 & ns & ns & ns \\
\hline $\mathrm{d} 0$ to 15 & 345.07 & 394.71 & 373.65 & 313.38 & 56.11 & ns & ns & ns \\
\hline d 0 to 21 & 458.59 & $527.04^{\mathrm{a}}$ & $474.17^{\mathrm{a}}$ & $387.27^{b}$ & 55.81 & ns & ns & 0.009 \\
\hline \multicolumn{9}{|l|}{$\mathrm{G}: \mathrm{F}^{3}$} \\
\hline d 0 to 7 & 0.59 & 0.48 & 0.70 & 0.57 & 0.27 & ns & ns & ns \\
\hline d 0 to 15 & $0.55^{b}$ & $0.75^{\mathrm{a}}$ & 0.71 & 0.67 & 0.16 & ns & ns & 0.033 \\
\hline d 0 to 21 & 0.62 & 0.73 & 0.70 & 0.70 & 0.08 & ns & ns & 0.050 \\
\hline
\end{tabular}

CR: sow diet with $\omega 6: \omega 3$ ratio $=13: 1$ during gestation, starting from day 28 (G28) and 10:1 during lactation; LR: sow diet with $\omega 6: \omega 3$ ratio $=4: 1$ from G28 until the end of lactation. CT: post-weaning piglets' diet supplemented without intact seaweed powder. SD: sow diets, PD: piglet diets. BW: body weight, ADG: average daily gain, ADFI: average daily feed intake, G:F: gain-to-feed ratio. * The trial was performed from weaning to day 21 of post-weaning with $4 \mathrm{~g}$ seaweed supplementation per $\mathrm{kg}$ of feed. Feed residual and daily feed intake of each piglet were recorded every morning, from day 0 (weaning) to day 21 post-weaning to calculate average daily feed intake and feed conversion ratio. Individual body weight of piglets was measured on day $0,7,15$ and 21 of post-weaning. ${ }^{* *}$ Piglets were kept in individual pens $(0.47 \mathrm{~m} 2)$ with ad libitum feed and water. ${ }^{1}$ SEM: Standard error of the means. ${ }^{a}$, b Means are presented as least square means. ${ }^{2}$ have normal distribution so mixed procedure was performed. ${ }^{3}$ do not have normal distribution so GENMOD procedure (using generalized estimating equations (GEE) method) was performed to fit the generalized linear models. ${ }^{4}$ ns: not significant.

\subsection{Fatty Acids Composition of Colostrum and Milk}

Low $\omega 6: \omega 3$ ratio in the maternal diet significantly influenced the fatty acids (FA) profile of both colostrum and milk (Figure 2). In the colostrum, low $\omega 6: \omega 3$ ratio reduced concentrations of $\gamma$-linolenic acid (GLA, C18:3 $\omega 6)$ by two-fold $(p<0.05)$. Low $\omega 6: \omega 3$ ratio also decreased the concentration of docosahexaenoic acid (DHA, C22:6 $\omega 3$ ) by two-fold and the overall $\omega 6: \omega 3$ ratio by one-third $(p<0.05)$. In the milk collected on day 7 , low $\omega 6: \omega 3$ ratio increased concentrations of total $\omega 3$ FAs and $\alpha$-linolenic acid (ALA, C18:3 $\omega 3$ ) by 1.6-fold $(p<0.01)$ and consequently decreased the overall $\omega 6: \omega 3$ ratio by one-third $(p=0.0001)$. In the milk collected at the end of lactation, low $\omega 6: \omega 3$ ratio increased concentrations of total $\omega 3$ FAs and $\alpha$-linolenic acid (ALA, C18:3 $\omega 3$ ) by three-fold $(p<0.0001$ ), increased concentration of eicosatrienoic acid (ETA, C20:3 $\omega 3$ ) by two-fold $(p<0.05)$, and also increased level of eicosapentaenoic acid (EPA; C20:5 $\omega 3)(p<0.01)$. Overall, $\omega 6: \omega 3$ ratio was two-thirds declined 
in the low ratio treatment $(p<0.0001)$. Interactions between sow diet and sampling point were significant in total $\omega 3, \alpha$-linolenic acid (ALA, C18:3 $\omega 3$ ) and the overall $\omega 6: \omega 3$ ratio.

\section{A1}

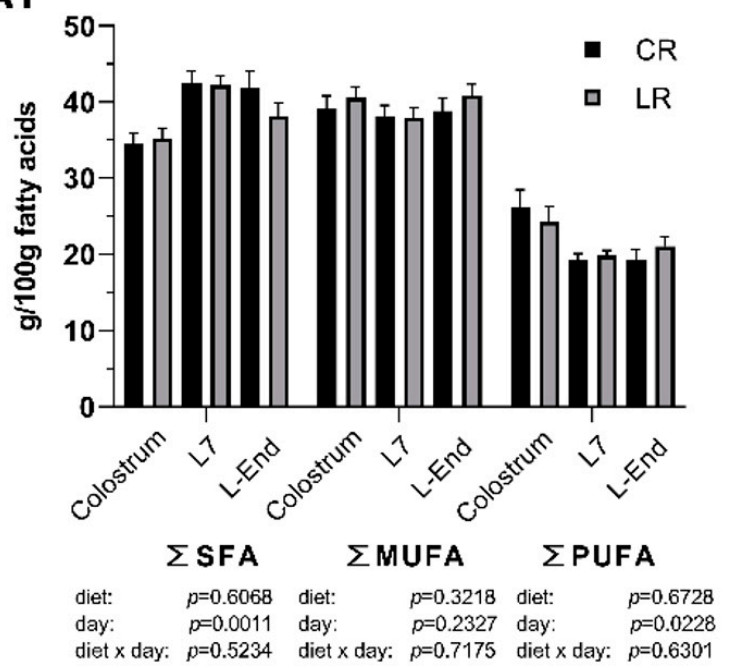

A4

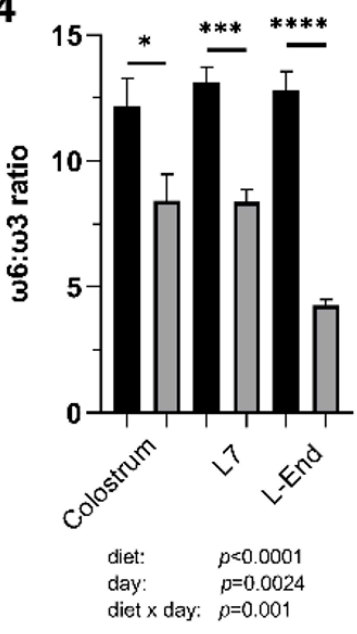

A2

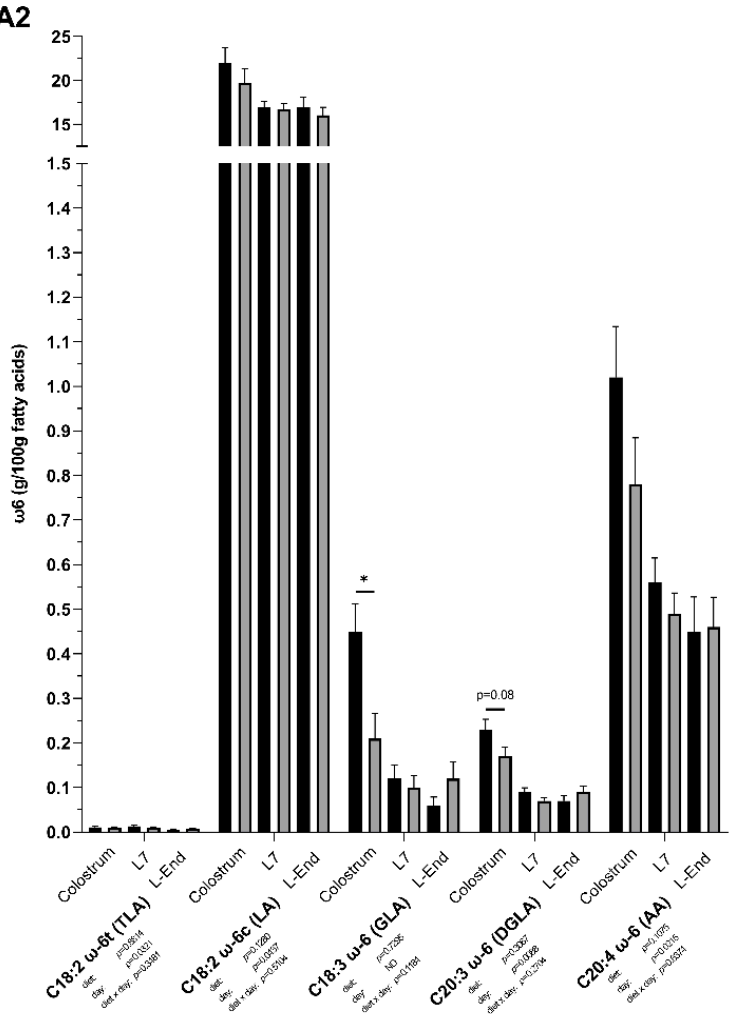

A3

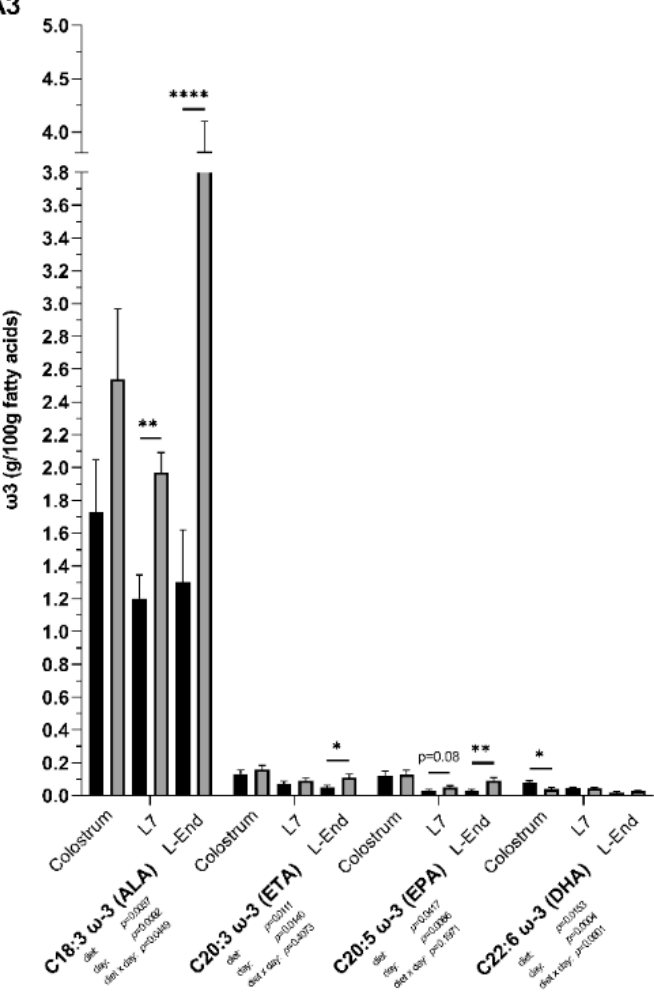

Figure 2. Fatty acid (FA) profile (g/100 g FAs) of colostrum and milk collected on day 7 (L7) and the end of lactation (L-End) from sows fed diets included $\omega 6: \omega 3$ ratio $=13: 1$ during gestation, starting from day 28 (G28) and 10:1 during lactation (CR) or w6:w3 ratio = 4:1 from G28 until L-End (LR). A1: SFA, MUFA and PUFA concentrations. A2: Individual concentrations of $\omega 6$ PUFAs. A3: Individual concentrations of $\omega 3$ PUFAs. A4: $\omega 6: \omega 3$ ratio. SFA $=$ Saturated FAs, MUFA $=$ Monounsaturated FAs, PUFA $=$ Polyunsaturated FAs, TLA $=$ Linoleaidic acid, LA $=$ Linoleic acid, GLA $=\gamma$-linolenic acid, DGLA $=$ dihomo- $\gamma$-linolenic acid, AA $=$ Arachidonic acid, ALA $=\alpha$-linolenic acid, ETA $=$ Eicosatrienoic acid, $\mathrm{EPA}=$ Eicosapentaenoic acid, DHA $=$ Docosahexaenoic acid. Data are $\mathrm{LSM} \pm \mathrm{SE} ; n=5,5$ and 6 for CR group and 6, 7, 8 for LR group for colostrum, milk collected at L7 and L-End. ${ }^{*} p<0.05,{ }^{* *} p<0.01$, ${ }^{* * *} p<0.001,{ }^{* * * *} p<0.0001$. 


\subsection{Leptin Concentrations and Oxidative Status in Sow Plasma}

Low dietary $\omega 6: \omega 3$ ratio (LR) had some effects on the concentrations of leptin and oxidative stress indicators in sow plasma (Figure 3). LR diet decreased concentrations of plasma leptin at L-End and d-ROMs at G28 ( $p<0.01)$ but had no effect on TBARS, AOPP, and FRAP levels at any time point. Regarding the impact of time on oxidative levels, concentrations of d-ROMs decreased in the middle of gestation and at the end of lactation but increased at the end of gestation and middle of lactation $(p<0.05)$. No interaction between diet and time point was explored for all measured indicators in sow plasma.

\section{A1}

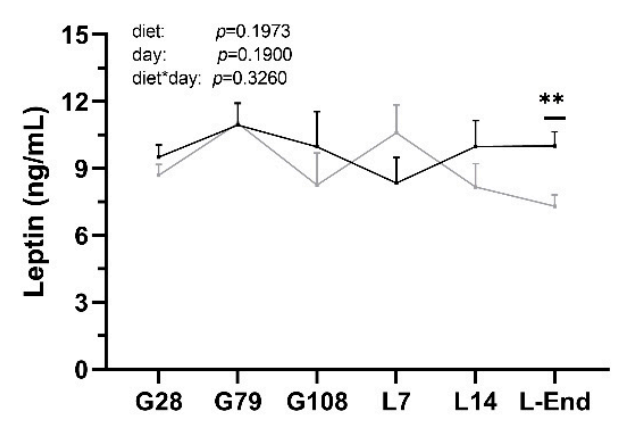

A3

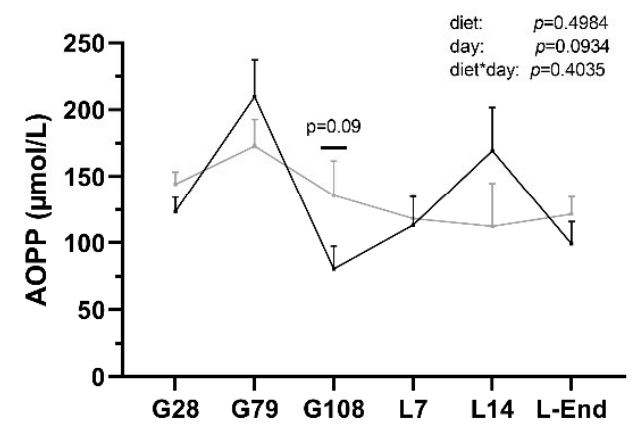

A5

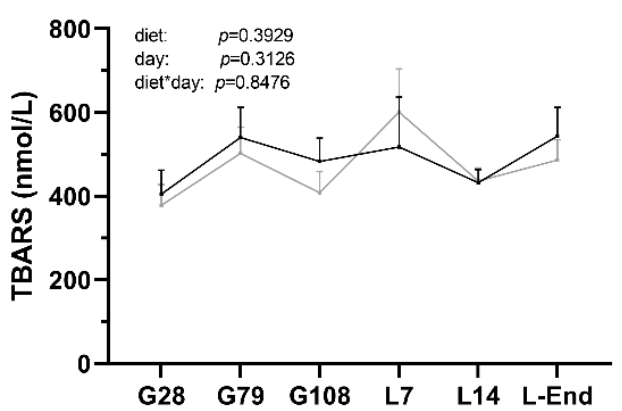

\section{A2}

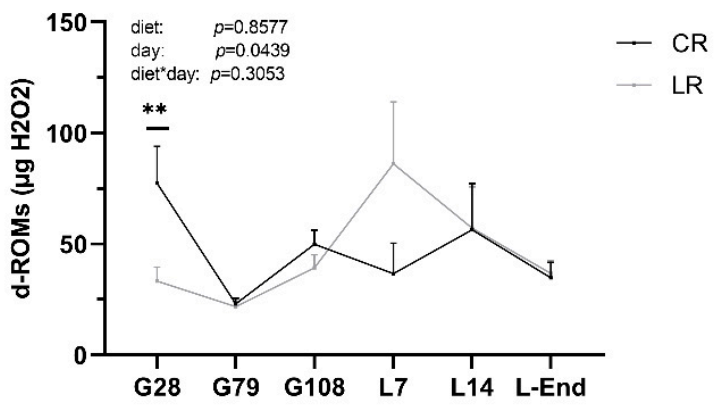

A4

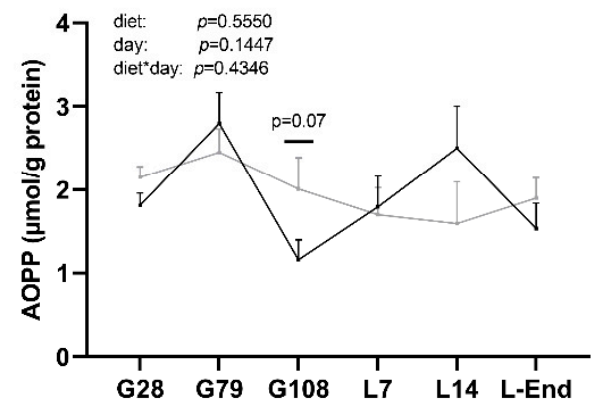

A6

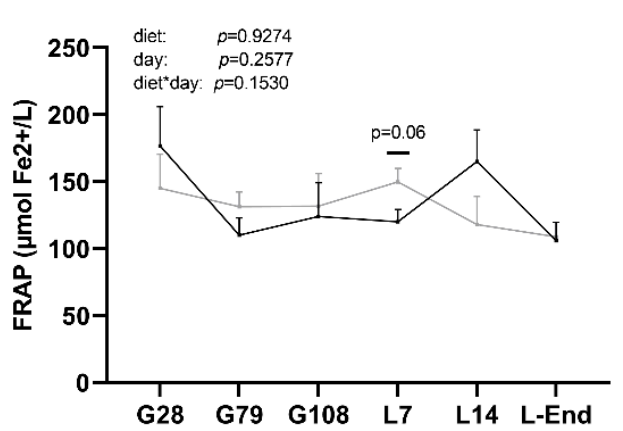

Figure 3. Concentrations of leptin and oxidative stress indicators of sow plasma during gestation and lactation periods. A1: Leptin; A2: The derivatives of reactive oxygen metabolites (d-ROMs); A3, A4: Advanced oxidation products of proteins (AOPP); A5: Thiobarbituric acid reactive substances (TBARS); A6: Ferric reducing ability of plasma (FRAP). CR: sow diet with $\omega 6: \omega 3$ ratio = 13:1 during gestation, starting from day 28 (G28) and 10:1 during lactation; LR: sow diet with $\omega 6: \omega 3$ ratio $=4: 1$ from G28 until L-End. G: days of gestation, L: days of lactation. Data are LSM \pm SE; $n=6-8$ sows per group. ${ }^{* *} p<0.01$. 


\subsection{Oxidative Status in Plasma of Post-Weaning Piglets}

Low maternal dietary $\omega 6: \omega 3$ ratio (LR) and seaweed supplementation (SW) in the post-weaning piglets' diet did not affect levels of d-ROMs in CRSW and LRCT piglets at weaning ( $p>0.05$, Figure 4$)$. LR diet increased concentrations of d-ROMs at d $21(p<0.05)$ : d-ROMs in LRSW piglets was 1.5-fold greater than LRCT and CRCT piglets and was 2-fold higher than CRSW piglets $(p=0.01)$.

A1

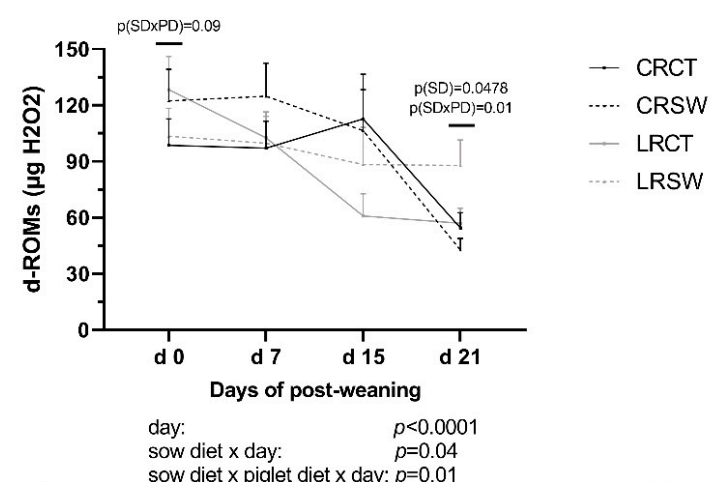

A2

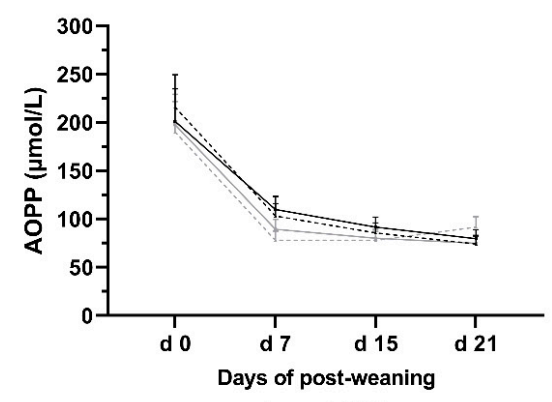

A4

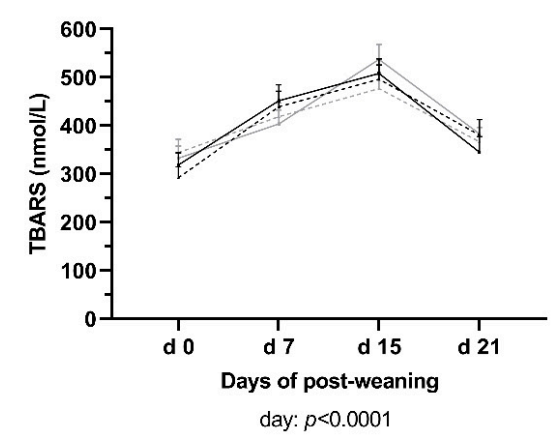

A3
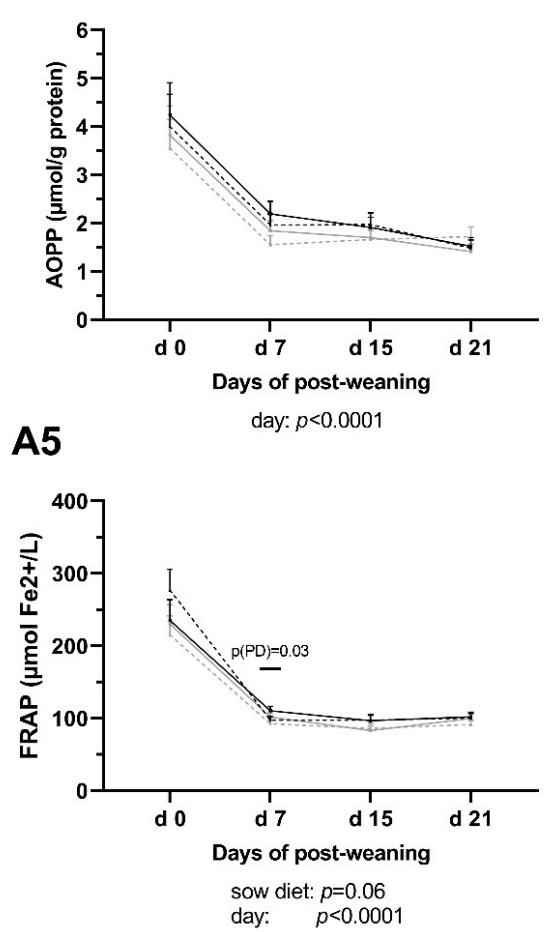

Figure 4. Concentrations of oxidative stress indicators of piglet plasma during the post-weaning period. A1: The derivatives of reactive oxygen metabolites (d-ROMs); A2: Advanced oxidation products of proteins (AOPP, $\mu \mathrm{mol} / \mathrm{L}$ ); A3: AOPP ( $\mu \mathrm{mol} / \mathrm{g}$ protein); A4: Thiobarbituric acid reactive substances (TBARS); A5: Ferric reducing ability of plasma (FRAP). CRCT: piglets fed no seaweed (SW, Ascophyllum nodosum), which were nursed by sows fed dietary $\omega 6: \omega 3$ ratio $=13: 1$ during gestation, starting from day 28 (G28) and 10:1 during lactation. CRSW: piglets fed SW, which were nursed by sows fed dietary $\omega 6: \omega 3$ ratio $=13: 1$ during gestation and 10:1 during lactation. LRCT: piglets fed no SW, which were nursed by sows fed dietary $\omega 6: \omega 3$ ratio $=4: 1$ from G28 until the end of lactation. LRSW: piglets fed SW, which were nursed by sows fed dietary $\omega 6: \omega 3$ ratio $=4: 1$ from G28 until the end of lactation. Data are $\mathrm{LSM} \pm \mathrm{SE} ; n=10$ piglets/group. SD, $\mathrm{PD}$, and $\mathrm{SD} \times \mathrm{PD}$ : effect of sow diet, piglet diet and their interaction between 4 groups at the same sample point. 
SW diet lowered concentration of FRAP at d $7(p<0.05)$ but LR diet did not affect levels of FRAP during post-weaning $(p>0.05)$. There were no effects of either sow diet, piglet diet, or their interaction on plasma concentrations of AOPP and TBARS at any time point.

The effects of time on all examined oxidative parameters were significant $(p<0.01)$. Interaction between sow diet and time point, between sow diet, piglet diet and time point were revealed for d-ROMs levels through the post-weaning period $(p<0.05)$.

\section{Discussion}

In this study, we examined whether a low $\omega 6: \omega 3$ ratio (LR) in the sow diet and the supplementation of $A$. nodosum for piglets during the post-weaning period can benefit piglet performance and oxidative status more than the respective single treatment provided to the mother or the piglet. We also considered the effects of low $\omega 6: \omega 3$ ratio in the sows' diet on reproduction, milk FA profile, plasma leptin concentrations, and oxidative status. We found that the LR diet enhanced total $\omega 3$ FA in colostrum and milk, weaning survival rate, and suckling piglets' weight gain. The interaction between CR and SW diets enhanced piglets' growth. But LR and SW diets did not affect growth and oxidative status in sows and post-weaning piglets.

We observed that LR diet increased weaning survival rate and sucking piglets' weight gain compared with the control diet. The enhancement of total $\omega 3$ PUFAs in the sows' colostrum and milk in LR diet could lead to a positive modulation of the intestinal microflora, thus promoting the intestinal health in suckling piglets by inhibiting Toll-like receptor 4 (TLR4) and signaling to reduce inflammation [30]. Our results support previous research findings that link low $\omega 6: \omega 3$ ratio in the maternal diet with piglet growth improvement. Specifically, a trend in improving piglets' growth rate in the first week of life was reported when a $\omega 6: \omega 3$ ratio of 5:1 was provided to sows compared to an 11:1 ratio [2]. Similarly, lowering dietary $\omega 6: \omega 3$ ratio from 20:1 and 15:1 to 10:1 increased piglet body weight and litter ADG at weaning [3]. Moreover, a 3:1 diet tended to increase litter size on the second and third weeks of life while a 9:1 diet tended to increase litter ADG in the first 14 days of age compared with a 13:1 diet [1]. In our study, LR sows had fewer piglets born alive than CR sows, but their performance was similar to previous research when sows were fed low $\omega 6: \omega 3$ ratios (from 1:1 to 5:1) [31]. The reduction in the number of piglets born alive on the LR diet is difficult to explain: it is not solely due to low dietary $\omega 6: \omega 3$ ratio, but also some unaccounted factors might be involved in the obtained results. The total number of piglets born and the number of born alive are affected by genetic factors of both sows and piglets [32]. However, these traits' heritability is low (ranging from 0.16 to 0.19 and 0.04 to 0.29 , respectively) [33,34]. Therefore, they are strongly affected by the environment. The low heritability of these parameters could explain for their variability between the sows and between CR and LR groups, although we kept these two groups in the same environmental conditions during the feeding trial.

To our knowledge, this is the first study that accounts for a possible combined positive effect of $\omega 3$ enriched maternal diet and seaweed supplementation in the post-weaning piglets' diet on their growth and oxidative status. Results showed that seaweed (A. nodosum) supplementation in post-weaning piglets increased BW, ADG, ADFI, and G:F when born from control sow compared with non-seaweed supplemented piglets. A. nodosum is considered to be a source of $\omega 3$ PUFAs with a high concentration of EPA (C20:5 $\omega 3)$ and low $\omega 6: \omega 3$ ratio of 2.75 [35]. Thus, this can add more $\omega 3$ PUFAs and lower $\omega 6: \omega 3$ ratios in piglets, which were born from control sows and received the seaweed diet. However, this positive result of additional $\omega 3$ PUFAs from A. nodosum was not seen in piglets born from sows fed $\omega 3$ enriched diet. Thus, the combined effect of LR and SW diets is difficult to explain. The literature reports that offering too low a ratio of $\omega 6: \omega 3$ (0.38) to pigs (from growing to finishing) did not affect their growth performance, although it improved total $\omega 3$ PUFAs (including ALA, EPA, and DHA) and reduced $\omega 6: \omega 3$ ratio in pork [36].

Lowering the ratio of $\omega 6: \omega 3$ PUFAs by adding linseed oil to the maternal diet can decrease $\omega 6: \omega 3$ ratio in colostrum and milk by enriching ALA concentration [1], thus, increasing concentrations of 
ALA in piglet liver, brain, and muscle tissues [37], plasma, carcass [38], and intestinal mucosa [39]. Our results are consistent with the findings of Yao et al. [1] when offering high ALA combined with the low LA diet.

However, high ALA intake was found not to affect the DHA level in piglet liver [6] or even decreased DHA concentration in human red blood cells, although it increased EPA level [40]. In line with recent research, the low concentration of DHA in our study was due to the inefficient conversion of ALA to EPA (i.e., 0.2 5\%) and DHA (i.e., 0.05-0.5\%) [41,42], which may be explained by several reasons: First, the high rate (59\%) of ALA was $\beta$-oxidized for the whole body utilization [43]. Second, the lack of elongase-2 expression to elongate C22:5 $\omega 3$ to C24:5 $\omega 3$ [44], which supports the EPA generation. Third, the competition between LA and ALA for enzyme $\Delta-6$ desaturase, which has a higher affinity for ALA; thus, high LA intake prevents the conversion from ALA to EPA [41,45]. Collectively, our results demonstrate that a linseed oil enriched $\omega 3$ diet is a substantial source for endogenous ALA rather than for endogenous DHA concentrations.

Leptin is an important adipocyte-secreted hormone regulating appetite, body weight, reproduction, energy homeostasis, and acts as a pro-inflammatory cytokine [46]. The $\omega 3$ enriched diet can regulate leptin in vivo [47]. It tended to decrease leptin in adipose tissue [48], and lower plasma leptin level [49]. In this study, the reducing effect of $\omega 3$ enriched diet on plasma leptin in sows at the end of lactation might go with increased $\beta$-oxidation of FAs in the liver and skeletal muscle (to a smaller extent) [50].

Pregnancy, delivery process, and lactation are all associated with elevated levels of oxidative stress due to intensive metabolism and lipid peroxidation [51]. We found that a low ratio of $\omega 6: \omega 3$ PUFAs in the maternal diet tended to increase AOPP concentrations at the end of gestation, decreased the number of piglets born and piglets born alive, which could be explained by the involvement of AOPP levels in embryonic mortality [52]. However, the increased level of AOPPs in LR sows did not seem to cause intracellular $\mathrm{ROS}\left(\mathrm{H}_{2} \mathrm{O}_{2}\right)$ production because d-ROMs levels were the same between LR and CR sows at the end of gestation. In this study, w3 enriched diet did not influence lipid peroxidation of sow plasma. It might be that the malondialdehyde measured in the TBARS test was absorbed quickly in the liver before being eliminated in urine without influencing TBARS levels in blood circulation [53]. Here, we observed that FRAP values of LR sows were similar at the end of gestation and tended to increase at the beginning of lactation, compared with CR sows. The hypothesis may explain that when protein oxidation increased, the sow's antioxidant system was stimulated and led to FRAP concentrations increasing when sows were offered more w3 PUFAs.

Weaning is a stressful event for piglets, challenging for health and growth due to various stressors [54]. The post-weaning period is associated with increased oxidative products in plasma: the highest ROM found in the first-week post-weaning was linked to reduced growth rates [55]; NO and $\mathrm{H}_{2} \mathrm{O}_{2}$ were highest at weaning and decreasing after weaning [56]. Similar results were observed in our study.

We could not see any effects of the low ratio of $\omega 6: \omega 3$ PUFAs in the maternal diet and seaweed supplementation in the piglets' diet on the piglets' oxidative status. However, the higher ADG and G:F ratio of the LRCT and CRSW piglets indicated benefits of $\omega 3$ enriched diet and seaweed supplementation on stimulating antioxidants to reduce excessive ROS production, therefore, improving piglets' growth performance. Growth performance reflects overall influences over a period, whereas plasma measurements are a single test at a time point [57]. Moreover, this improvement can be explained by the bioactivity of $\omega 3$ PUFAs in the maternal diet and seaweed-derived elements (i.e., ascophyllan, laminarin, fucoidans, and phlorotannins) in the post-weaning piglet diet [58]. Maternal diets enriched in $\omega 3$ PUFAs with optimal $\omega 6: \omega 3$ ratio might regulate progeny immune response and improve anti-inflammatory activity against pathogens [59], especially the inflammatory response causing by post-weaning stress [4]. Post-weaning diets supplemented with A. nodosum can promote piglet intestinal health through its immunomodulatory, anti-inflammatory, antioxidant, and antimicrobial properties [60-62], thereby improving piglets' growth rates. 
Overall, our study showed that the $w 3$ enriched diet during gestation and lactation did not affect the oxidative stress of sows and their post-weaning piglets. Similar results were reported when feeding a dietary $\omega 6: \omega 3$ ratio of $4: 1$ or $6: 1$ to sows [6] or feeding a dietary $\omega 6: \omega 3$ ratio of $5: 1$ to piglets (10.6 kg) [63]. These outcomes may be explained by low double bonds of ALA and its poor conversion rate to EPA and DHA, as shown in the FA profile of colostrum and milk in this study. The dietary $\omega 6: \omega 3$ ratio above 3:1 is considered safe to protect the animal from oxidative damage [5]. Our results suggest that not only the dietary ratio between $\omega 6$ and $\omega 3$ but also the type of fat source (total double bonds) have synergic effects on the oxidative stress level of the sows and piglets.

\section{Conclusions}

The current study showed that low dietary $\omega 6: \omega 3$ ratio in sow diet during gestation and lactation combined with the seaweed supplementation in piglets after weaning could not improve piglets' growth rate or antioxidant status. However, the sows' low $\omega 6: \omega 3$ ratio diet alone improved weaning survival rate, suckling piglets' weight gain, and total w3 PUFAs (mainly ALA) in the colostrum and milk. Seaweed supplementation improved growth performance of piglets born from sows which received the higher dietary $\omega 6: \omega 3$ ratio. These findings outline that maternal dietary interventions can significantly affect the progeny, and that seaweed supplementation is effective in improving performance in post-weaning piglets. However, interaction among these treatments remains unclear. Further studies are necessary to enhance the knowledge of maternal dietary interventions during gestation and lactation, and their effect on the progeny or to outline the efficacy of natural antimicrobials and antioxidants in the diets of piglets, also considering omics and epigenetic approaches.

Supplementary Materials: The following are available online at http://www.mdpi.com/2076-2615/10/11/2049/s1, Table S1: Growth performance of post-weaning piglets fed seaweed (SW).

Author Contributions: Conceptualization, A.A., V.B., and G.S.; Methodology, A.A., G.S., S.P., H.S., and I.G.; Software, T.X.N. and A.A.; Validation, T.X.N. and A.A.; Formal analysis, T.X.N. and A.A.; Investigation, A.A., M.C., T.X.N., and I.G.; Resources, A.A., M.C., V.B., G.S., S.P., and H.S.; Data curation, T.X.N., A.A., and M.C.; Writing-original draft, T.X.N.; Writing—review and editing, T.X.N., G.S., A.A., H.S., P.D.E., and R.B.; Visualization, T.X.N.; Supervision, G.S., A.A., R.B., and P.D.E.; Project administration, G.S. and A.A.; Funding acquisition, G.S. All authors have read and agreed to the published version of the manuscript.

Funding: This project has received funding from the European Union's Horizon 2020 research and innovation programme H2020-MSCA-ITN-2017-EJD under the Marie Skłodowska-Curie Innovative Training Networks (European Joint Doctorate in Molecular Animal Nutrition, MANNA), grant agreement No 765423.

Acknowledgments: We thank Vera Perricone, Jacopo Ranghetti, and Francesca Maffetti for help with the in-vivo trials, Barbara Heitkoenig and Thomas Blees for technical assistance.

Conflicts of Interest: The authors declare no conflict of interest. The funders had no role in the design of the study; in the collection, analyses, or interpretation of data; in the writing of the manuscript, or in the decision to publish the results.

\section{References}

1. Yao, W.; Li, J.; Wang, J.; Zhou, W.; Wang, Q.; Zhu, R.; Wang, F.; Thacker, P. Effects of dietary ratio of n-6 to n-3 polyunsaturated fatty acids on immunoglobulins, cytokines, fatty acid composition, and performance of lactating sows and suckling piglets. J. Anim. Sci. Biotechnol. 2012, 3, 1-8. [CrossRef] [PubMed]

2. De Greeff, A.; Bikker, P.; Bruininx, E.; Zwolschen, H.; Fijten, H.; Zetteler, P. Increased fat and polyunsaturated fatty acid content in sow gestation diet has no effect on gene expression in progeny during the first 7 days of life. J. Anim. Physiol. Anim. Nutr. 2016, 100, 127-135. [CrossRef] [PubMed]

3. Yin, J.; Lee, K.Y.; Kim, J.K.; Kim, I.H. Effects of different n-6 to n-3 polyunsaturated fatty acids ratio on reproductive performance, fecal microbiota and nutrient digestibility of gestation-lactating sows and suckling piglets. Anim. Sci. J. 2017, 88, 1744-1752. [CrossRef] [PubMed]

4. McAfee, J.M.; Kattesh, H.G.; Lindemann, M.D.; Voy, B.H.; Kojima, C.J.; Burdick Sanchez, N.C.; Carroll, J.A.; Gillespie, B.E.; Saxton, A.M. Effect of omega-3 polyunsaturated fatty acid (n-3 PUFA) supplementation to lactating sows on growth and indicators of stress in the postweaned pig. J. Anim. Sci. 2019, 97, 4453-4463. [CrossRef] [PubMed] 
5. Yang, Y.Y.; Hu, C.J.; Zhao, X.C.; Xiao, K.L.; Deng, M.; Zhang, L.; Qiu, X.G.; Deng, J.P.; Yin, Y.L.; Tan, C.Q. Dietary energy sources during late gestation and lactation of sows: Effects on performance, glucolipid metabolism, oxidative status of sows and their offspring. J. Anim. Sci. 2019, 97, 4608-4618. [CrossRef] [PubMed]

6. Tanghe, S.; Missotten, J.; Raes, K.; De Smet, S. The effect of different concentrations of linseed oil or fish oil in the maternal diet on the fatty acid composition and oxidative status of sows and piglets. J. Anim. Physiol. Anim. Nutr. 2015, 99, 938-949. [CrossRef]

7. Simopoulos, A.P. An increase in the Omega-6/Omega-3 fatty acid ratio increases the risk for obesity. Nutrients 2016, 8, 128. [CrossRef]

8. Heshmati, J.; Morvaridzadeh, M.; Maroufizadeh, S.; Akbari, A.; Yavari, M.; Amirinejad, A.; Maleki-Hajiagha, A.; Sepidarkish, M. Omega-3 fatty acids supplementation and oxidative stress parameters: A systematic review and meta-analysis of clinical trials. Pharmacol. Res. 2019, 149. [CrossRef]

9. Campbell, J.M.; Crenshaw, J.D.; Polo, J. The biological stress of early weaned piglets. J. Anim. Sci. Biotechnol. 2013, 4, 2-5. [CrossRef]

10. Ahasan, A.S.M.L.; Invernizzi, G.; Farina, G.; Pilotto, A.; Barbé, F.; Bontempo, V.; Rossi, R.; Bellagamba, F.; Lecchi, C.; Savoini, G.; et al. The effects of superoxide dismutase-rich melon pulp concentrate on inflammation, antioxidant status and growth performance of challenged post-weaning piglets. Animals 2019, 13, 136-143. [CrossRef]

11. Xiong, X.; Tan, B.; Song, M.; Ji, P.; Kim, K.; Yin, Y.; Liu, Y. Nutritional intervention for the intestinal development and health of weaned pigs. Front. Vet. Sci. 2019, 6, 1-14. [CrossRef]

12. Agazzi, A.; Perricone, V.; Zorini, F.O.; Sandrini, S.; Mariani, E.; Jiang, X.; Ferrari, A.; Crestani, M.; Nguyen, T.X.; Bontempo, V.; et al. Dietary Mannan Oligosaccharides Modulate Gut Inflammatory Response and Improve Duodenal Villi Height in Post-Weaning Piglets Improving Feed Efficiency. Animals 2020, 4, 1283. [CrossRef]

13. Perricone, V.; Comi, M.; Bontempo, V.; Lecchi, C.; Ceciliani, F.; Crestani, M.; Ferrari, A.; Savoini, G.; Perricone, V.; Comi, M.; et al. Effects of nucleotides administration on growth performance and immune response of post- weaning piglets. Ital. J. Anim. Sci. 2020, 19, 295-301. [CrossRef]

14. Jacobsen, C.; Sørensen, A.-D.M.; Holdt, S.L.; Akoh, C.C.; Hermund, D.B. Source, Extraction, Characterization, and Applications of Novel Antioxidants from Seaweed. Annu. Rev. Food Sci. Technol. 2019, 10, 541-568. [CrossRef] [PubMed]

15. Ford, L.; Stratakos, A.C.; Theodoridou, K.; Dick, J.T.A.; Sheldrake, G.N.; Linton, M.; Corcionivoschi, N.; Walsh, P.J. Polyphenols from Brown Seaweeds as a Potential Antimicrobial Agent in Animal Feeds. ACS Omega 2020, 5, 9093-9103. [CrossRef]

16. Pisoschi, A.M.; Pop, A. The role of antioxidants in the chemistry of oxidative stress: A review. Eur. J. Med. Chem. 2015, 97, 55-74. [CrossRef]

17. Turner, J.L.; Dritz, S.S.; Higgins, J.J.; Minton, J.E. Effects of Ascophyllum nodosum extract on growth performance and immune function of young pigs challenged with Salmonella typhimurium. J. Anim. Sci. 2002, 80, 1947-1953. [CrossRef]

18. Michiels, J.; Skrivanova, E.; Missotten, J.; Ovyn, A.; Mrazek, J.; De Smet, S.; Dierick, N. Intact brown seaweed (Ascophyllum nodosum) in diets of weaned piglets: Effects on performance, gut bacteria and morphology and plasma oxidative status. J. Anim. Physiol. Anim. Nutr. 2012, 96, 1101-1111. [CrossRef]

19. National Research Council. Nutrient Requirements of Swine, 11th ed; The National Academies Press: Washington, DC, USA, 2012; ISBN 978-0-309-22423-9.

20. Canadian Pork Council and the National Farm Animal Care Council. National Farm Animal Care Council Code of Practice: For the Care and Handling of Pigs; 2014; pp. 1-75, ISBN 978-0-993-61892-5. Available online: https:// www.albertapork.com/wp-content/uploads/2017/06/pig_code_of_practice.pdf (accessed on 30 October 2018).

21. Folch, J.; Lees, M.; Sloane Stanley, G.H. A simple method for the isolation and purification of total lipids from animal tissues. J. Biol. Chem. 1957, 226, 497-509.

22. Moltó-Puigmartí, C.; Castellote, A.I.; López-Sabater, M.C. Conjugated linoleic acid determination in human milk by fast-gas chromatography. Anal. Chim. Acta 2007, 602, 122-130. [CrossRef] [PubMed]

23. Sauerwein, H.; Heintges, U.; Hennies, M.; Selhorst, T.; Daxenberger, A. Growth hormone induced alterations of leptin serum concentrations in dairy cows as measured by a novel enzyme immunoassay. Livest. Prod. Sci. 2004, 87, 189-195. [CrossRef] 
24. Alberti, A.; Bolognini, L.; Macciantelli, D.; Caratelli, M. The radical cation of N,N-diethl-paraphenylendiamine: A possible indicator of oxidative stress in biological samples. Res. Chem. Intermed. 2000, 26, 253-267. [CrossRef]

25. Regenhard, P.; Nakov, D.; Sauerwein, H. Applicability of a spectrophotometric method for assessment of oxidative stress in poultry. Maced. Vet. Rev. 2014, 37, 43-47. [CrossRef]

26. Witko-Sarsat, V.; Friedlander, M.; Capeillère-Blandin, C.; Nguyen-Khoa, T.; Nguyen, A.T.; Zingraff, J.; Jungers, P.; Descamps-Latscha, B. Advanced oxidation protein products as a novel marker of oxidative stress in uremia. Kidney Int. 1996, 49, 1304-1313. [CrossRef]

27. Bradford, M.M. A rapid and sensitive method for the quantitation of microgram quantities of protein utilizing the principle of protein-dye binding. Anal. Biochem. 1976, 72, 248-254. [CrossRef]

28. Gutteridge, J.M.C.; Quinlan, G.J. Malondialdehyde formation from lipid peroxides in the thiobarbituric acid test: The role of lipid radicals, iron salts, and metal chelators. J. Appl. Biochem. 1983, 5, 293-299.

29. Benzie, I.F.F.; Strain, J.J. The ferric reducing ability of plasma (FRAP) as a measure of "antioxidant power": The FRAP assay. Anal. Biochem. 1996, 239, 70-76. [CrossRef]

30. Chen, J.; Xu, Q.; Li, Y.; Tang, Z.; Sun, W.; Zhang, X.; Sun, J.; Sun, Z. Comparative effects of dietary supplementations with sodium butyrate, medium-chain fatty acids, and n-3 polyunsaturated fatty acids in late pregnancy and lactation on the reproductive performance of sows and growth performance of suckling piglets. J. Anim. Sci. 2019, 97, 4256-4267. [CrossRef]

31. Cools, A.; Maes, D.; Papadopoulos, G.; Vandermeiren, J.A.; Meyer, E.; Demeyere, K.; De Smet, S.; Janssens, G.P.J. Dose-response effect of fish oil substitution in parturition feed on erythrocyte membrane characteristics and sow performance. J. Anim. Physiol. Anim. Nutr. 2011, 95, 125-136. [CrossRef]

32. Lund, M.S.; Puonti, M.; Rydhmer, L.; Jensen, J. Relationship between litter size and perinatal and pre-weaning survival in pigs. Anim. Sci. 2002, 74, 217-222. [CrossRef]

33. Dobrzański, J.; Sell-kubiak, E.; Knol, E.F. Estimation of litter size variability phenotypes in Large White sows. J. Anim. Breed. Genet. 2020, 137, 559-570. [CrossRef]

34. Camargo, E.G.; Marques, D.B.D.; De Figueiredo, E.A.P.; Silva, F.F.; Lopes, P.S. Genetic study of litter size and litter uniformity in Landrace pigs. Rev. Bras. Zootec. 2020, 49, 1-12. [CrossRef]

35. Van Ginneken, V.J.T.; Helsper, J.P.F.G.; De Visser, W.; Van Keulen, H.; Brandenburg, W.A. Polyunsaturated fatty acids in various macroalgal species from north Atlantic and tropical seas. Lipids Health Dis. 2011, 10, 4-11. [CrossRef] [PubMed]

36. Leikus, R.; Juskiene, V.; Juska, R.; Juodka, R.; Stankeviciene, D.; Nainiene, R.; Siukscius, A. Effect of linseed oil sediment in the diet of pigs on the growth performance and fatty acid profile of meat. Rev. Bras. Zootec. 2018, 47, 1-8. [CrossRef]

37. Tanghe, S.; Millet, S.; Missotten, J.; Vlaeminck, B.; De Smet, S. Effects of birth weight and maternal dietary fat source on the fatty acid profile of piglet tissue. Animals 2014, 8, 1857-1866. [CrossRef]

38. De Quelen, F.; Boudry, G.; Mourot, J. Linseed oil in the maternal diet increases long chain-PUFA status of the foetus and the newborn during the suckling period in pigs. Br. J. Nutr. 2010, 104, 533-543. [CrossRef]

39. Zhu, H.; Wang, H.; Wang, S.; Tu, Z.; Zhang, L.; Wang, X.; Hou, Y.; Wang, C.; Chen, J.; Liu, Y. Flaxseed Oil Attenuates Intestinal Damage and Inflammation by Regulating Necroptosis and TLR4/NOD Signaling Pathways Following Lipopolysaccharide Challenge in a Piglet Model. Mol. Nutr. Food Res. 2018, 62, 1-11. [CrossRef]

40. Greupner, T.; Kutzner, L.; Nolte, F.; Strangmann, A.; Kohrs, H.; Hahn, A.; Schebb, N.H.; Schuchardt, J.P. Effects of a 12-week high- $\alpha$-linolenic acid intervention on EPA and DHA concentrations in red blood cells and plasma oxylipin pattern in subjects with a low EPA and DHA status. Food Funct. 2018, 9, 1587-1600. [CrossRef]

41. Burdge, G.C.; Calder, P.C. Conversion of $\alpha$-linolenic acid to longer-chain polyunsaturated fatty acids in human adults. Reprod. Nutr. Dev. 2005, 45, 581-597. [CrossRef]

42. Plourde, M.; Cunnane, S.C. Extremely limited synthesis of long chain polyunsaturates in adults: Implications for their dietary essentiality and use as supplements. Appl. Physiol. Nutr. Metab. 2007, 32, 619-634. [CrossRef]

43. Poumès-Ballihaut, C.; Langelier, B.; Houlier, F.; Alessandri, J.M.; Durand, G.; Latge, C.; Guesnet, P. Comparative bioavailability of dietary $\alpha$-linolenic and docosahexaenoic acids in the growing rat. Lipids 2001, 36, 793-800. [CrossRef] 
44. Barceló-Coblijn, G.; Murphy, E.J. Alpha-linolenic acid and its conversion to longer chain n-3 fatty acids: Benefits for human health and a role in maintaining tissue n-3 fatty acid levels. Prog. Lipid Res. 2009, 48, 355-374. [CrossRef]

45. Greupner, T.; Kutzner, L.; Pagenkopf, S.; Kohrs, H.; Hahn, A.; Schebb, N.H.; Schuchardt, J.P. Effects of a low and a high dietary LA/ALA ratio on long-chain PUFA concentrations in red blood cells. Food Funct. 2018, 9, 4742-4754. [CrossRef]

46. Gruzdeva, O.; Borodkina, D.; Uchasova, E.; Dyleva, Y.; Barbarash, O. Leptin resistance: Underlying mechanisms and diagnosis. Diabetes Metab. Syndr. Obes. Targets Ther. 2019, 12, 191-198. [CrossRef]

47. Fukumitsu, S.; Aida, K.; Ueno, N.; Ozawa, S.; Takahashi, Y.; Kobori, M. Flaxseed lignan attenuates high-fat diet-induced fat accumulation and induces adiponectin expression in mice. Br. J. Nutr. 2008, 100, 669-676. [CrossRef]

48. Baranowski, M.; Enns, J.; Blewett, H.; Yakandawala, U.; Zahradka, P.; Taylor, C.G. Dietary flaxseed oil reduces adipocyte size, adipose monocyte chemoattractant protein-1 levels and T-cell infiltration in obese, insulin-resistant rats. Cytokine 2012, 59, 382-391. [CrossRef]

49. Tekeleselassie, A.W.; Goh, Y.M.; Rajion, M.A.; Motshakeri, M.; Ebrahimi, M. A high-fat diet enriched with low omega-6 to omega-3 fatty acid ratio reduced fat cellularity and plasma leptin concentration in sprague-dawley rats. Sci. World J. 2013, 2013, 1-7. [CrossRef]

50. Ukropec, J.; Reseland, J.E.; Gasperikova, D.; Demcakova, E.; Madsen, L.; Berge, R.K.; Rustan, A.C.; Klimes, I.; Drevon, C.A.; Sebökova, E. The Hypotriglyceridemic Effect of Dietary n-3 FA Is Associated with Increased $\beta$-Oxidation and Reduced Leptin Expression. Lipids 2003, 38, 1023-1029. [CrossRef]

51. Camkurt, M.A.; Findikli, E.; Tolun, F.I.; Bakacak, M.; Bal, N.G.; Sakalli, H.; Güneş, M. Probable preventive effects of placenta from oxidative stress; Evaluation of total antioxidant status, total oxidant status and oxidative stress index in fetal cord blood during the delivery. Psychiatry Res. 2016, 240, 222-225. [CrossRef]

52. Celi, P.; Merlo, M.; Da Dalt, L.; Stefani, A.; Barbato, O.; Gabai, G. Relationship between late embryonic mortality and the increase in plasma advanced oxidised protein products (AOPP) in dairy cows. Reprod. Fertil. Dev. 2011, 23, 527-533. [CrossRef] [PubMed]

53. Lindblom, S.C. Impacts of Feeding Peroxidized Oils on Growth and Oxidative Status in Swine and Poultry. Master's Thesis, Iwoa State University, Ames, IA, USA, 2017.

54. Barba-Vidal, E.; Martín-Orué, S.M.; Castillejos, L. Review: Are we using probiotics correctly in post-weaning piglets? Animals 2018, 12, 2489-2498. [CrossRef]

55. Sauerwein, H.; Schmitz, S.; Hiss, S. Effects of a dietary application of a yeast cell wall extract on innate and acquired immunity, on oxidative status and growth performance in weanling piglets and on the ileal epithelium in fattened pigs. J. Anim. Physiol. Anim. Nutr. 2007, 91, 369-380. [CrossRef]

56. Zhu, L.H.; Zhao, K.L.; Chen, X.L.; Xu, J.X. Impact of weaning and an antioxidant blend on intestinal barrier function and antioxidant status in pigs. J. Anim. Sci. 2012, 90, 2581-2589. [CrossRef] [PubMed]

57. Silva-Guillen, Y.V.; Arellano, C.; Boyd, R.D.; Martinez, G.; Van Heugten, E. Growth performance, oxidative stress and immune status of newly weaned pigs fed peroxidized lipids with or without supplemental vitamin e or polyphenols. J. Anim. Sci. Biotechnol. 2020, 11,1-11. [CrossRef]

58. Makkar, H.P.S.; Tran, G.; Heuzé, V.; Giger-Reverdin, S.; Lessire, M.; Lebas, F.; Ankers, P. Seaweeds for livestock diets: A review. Anim. Feed Sci. Technol. 2016, 212, 1-17. [CrossRef]

59. Lee, A.V.; You, L.; Oh, S.Y.; Li, Z.; Fisher-Heffernan, R.E.; Regnault, T.R.H.; de Lange, C.F.M.; Huber, L.; Karrow, N.A. Microalgae supplementation to late gestation sows and its effects on the health status of weaned piglets fed diets containing high- or low-quality protein sources. Vet. Immunol. Immunopathol. 2019, 218. [CrossRef]

60. Bahar, B.; O'Doherty, J.V.; Smyth, T.J.; Sweeney, T. A comparison of the effects of an Ascophyllum nodosum ethanol extract and its molecular weight fractions on the inflammatory immune gene expression in-vitro and ex-vivo. Innov. Food Sci. Emerg. Technol. 2016, 37, 276-285. [CrossRef]

61. Corona, G.; Ji, Y.; Anegboonlap, P.; Hotchkiss, S.; Gill, C.; Yaqoob, P.; Spencer, J.P.E.; Rowland, I. Gastrointestinal modifications and bioavailability of brown seaweed phlorotannins and effects on inflammatory markers. Br. J. Nutr. 2016, 115, 1240-1253. [CrossRef] 
62. Dell'Anno, M.; Sotira, S.; Rebucci, R.; Reggi, S.; Castiglioni, B.; Rossi, L. In vitro evaluation of antimicrobial and antioxidant activities of algal extracts. Ital. J. Anim. Sci. 2020, 19, 103-113. [CrossRef]

63. Leskovec, J.; Rezar, V.; Svete, A.N. Antioxidative effects of olive polyphenols compared to vitamin e in piglets fed a diet rich in n-3 pufa. Animals 2019, 9, 161. [CrossRef]

Publisher's Note: MDPI stays neutral with regard to jurisdictional claims in published maps and institutional affiliations.

(C) 2020 by the authors. Licensee MDPI, Basel, Switzerland. This article is an open access article distributed under the terms and conditions of the Creative Commons Attribution (CC BY) license (http://creativecommons.org/licenses/by/4.0/). 